\title{
MOBILE COMMUNICATION - PAST, PRESENT AND FUTURE: A REVIEW
}

\author{
NANDHAKUMAR PANDI ${ }^{1}$, MOHSIN NARGUND $^{2}$ \\ ${ }^{1}$ Network Operation Associate, Nokia- Alcatel Lucent, Bangalore, India, ${ }^{2}$ Assistant Manager, Relience Jio, Nippani, \\ Karnataka, India. \\ Email: nandhakumar.pandi.ext@nokia.com,mosinnaragund@gmail.com
}

\begin{abstract}
Communication is one of the most important things in human life, day by day the technology is changing, data rate becomes faster and equipment's are also becoming compact, as the results of change in technology. The human beings have also adapted to the technology as well. In this article the revolution of wireless technologies like $2 G, 3 G, 4 G$ and $5 G$ (Future generation network) are explained. This article mainly focused on background of wireless communication system, models and technologies adapted for $4 G$ and 5G. The key technologies, spectrum allocation and current projects are discussed and described; this work gives a detailed research to address the projects and developments for future generation wireless technology.
\end{abstract}

Keywords: CDMA, OFDM, MIMO, 5G Projects, 5G technologies.

\section{INTRODUCTION}

In the upcoming years the consumption of data is going to increase drastically, which may cause the traffic or the consumption in the bandwidth, which won't be supported by $3 \mathrm{G}, 4 \mathrm{G}$ technologies, for that purpose, should go for the future wireless communication system, which should have a proper utilization of bandwidth. Presently a lot of researches are working on 5G technologies, so accordingly the next expected technology will be 5G [1]. Presently, 2G, 2.5G, 3G, 3.5G, 4G-LTE (Long Term Evolution) technologies are playing more important role in mobile communication system How? In $2 \mathrm{G}$ wireless standards has $(2 \mathrm{G}, 2.5 \mathrm{G})$ ended voice calling facility from mobile to mobile communication, and also it enables internet access. Over cellular networks, the another competing technology is $2.75 \mathrm{G}$ standard, i.e. EDGE (Enhanced Data for GSM Evolution). As the 2G technology grows rapidly, the number of $2 \mathrm{G}$ users becomes more, due to this effect lack of bandwidth consumption occurred, as well as demand for voice call, video conferencing also increased, but $2 \mathrm{G}$ technologies have limitations on data rate and bandwidth which tends to the development of $3 \mathrm{G}$ cellular wireless standards. In $3 \mathrm{G}$, the standards used are WCDMA/ UMTS, CDMA2000, HSDPA/HSUPA, 1EVDO this result in increased data rate and it enables video conferencing, although the bandwidth is not properly utilizing, this leads to the multicarrier technology [2]. In this multicarrier modulation technique, the carrier is subdivided into a number of small limited carriers. Each subcarrier will be independent of each other, there will be no inter carrier interference, this technique is known as Orthogonal Frequency Division Multiplexing (OFDM), which is adopted in current 4G LTE technology. This technique is very fast at data rate, as compared with the previous technology (3G), high spectrum efficiency and enhanced security [3]. In today's Business world 4G LTE technology plays a vital role, around 1.3 billion people are getting benefit from this technology. LTE not only provides super-fast connectivity to millions of users, but can also act as an enterprise, network connectivity enables. Although there are some disadvantages of the $4 \mathrm{G}$ LTE system, i.e. there is no proper utilization of bandwidth in 4G Worldwide Interoperability for Microwave Access (WiMax) OFDM system, around 11\% of bandwidth wasted because of insertion of cyclic prefix, this leads to the more enhanced upcoming $5 \mathrm{G}$ technology. All over the world the researches are going on, on 5G technology, but there is lots still to work out, 5G start to roll out until at least 2020 [4]. In the following section's background of mobile communication, technology and techniques adopted for $3 \mathrm{G}, 4 \mathrm{G}$ and $5 \mathrm{G}$ system, projects for $5 \mathrm{G}$ technology are explained.

\section{CELlular BACKGROUND}

COMMUNICATION

What is Communication? Communication is exchanging of information from one location to another location through some medium or channel, information in the form of voice, images and videos. The families of $2 \mathrm{G}, 3 \mathrm{G}, 4 \mathrm{G}$ wireless systems and standards are shown in Table 1. 
Table 1. Families of 2G, 3G, 4G wireless communication standards

\begin{tabular}{|c|c|c|c|}
\hline \multicolumn{4}{|c|}{ 2G Wireless Standards } \\
\hline Generation & Standards & Data Rate & Application \\
\hline $2 \mathrm{G}$ & GSM & $10 \mathrm{Kbps}$ & \multirow{4}{*}{ Voice + Data } \\
\hline $2 \mathrm{G}$ & CDMA & $10 \mathrm{Kbps}$ & \\
\hline $2.5 \mathrm{G}$ & GPRS & $50 \mathrm{Kbps}$ & \\
\hline $2.5 \mathrm{G}$ & EDGE & $200 \mathrm{Kbps}$ & \\
\hline \multicolumn{4}{|c|}{ 3G Wireless Standards } \\
\hline $3 G$ & WCDMA/UMTS & $384 \mathrm{Kbps}$ & \multirow{4}{*}{$\begin{array}{c}\text { Voice }+ \text { Data }+ \text { video } \\
\text { Calling }\end{array}$} \\
\hline $3 \mathrm{G}$ & CDMA 2000 & $384 \mathrm{Kbps}$ & \\
\hline $3.5 \mathrm{G}$ & HSDPA/HSUPA & 5-30 Mbps & \\
\hline $3.5 \mathrm{G}$ & $1 \mathrm{XEVDO}$ & 5-30 Mbps & \\
\hline \multicolumn{4}{|c|}{ 4G Wireless Standards } \\
\hline $4 \mathrm{G}$ & LTE & $100-200 \mathrm{Mbps}$ & \multirow{2}{*}{$\begin{array}{c}\text { Online Gaming, } \\
\text { HDTV }\end{array}$} \\
\hline $4 \mathrm{G}$ & WIMAX & $100-200 \mathrm{Mbps}$ & \\
\hline
\end{tabular}

The result of increasing demand for high bandwidth application has progressively developed the $3 \mathrm{G}$ and $4 \mathrm{G}$ wireless communication technology [5].

\subsection{Ideas of Wireless Communication}

A wireless communication system typically contains Base Station (BS) and Mobile Station (MS). BS will transmit an electromagnetic signal to the MS (User). MS will receive the transmitted signal from the BS. In addition to the direct propagation between BS and MS, there are also several reflected components that arise in the wireless environment namely trees, buildings and moving vehicles. These additional components are called as scatterers. Pictorial representation of idea of mobile communication environment is shown in Figure 1.

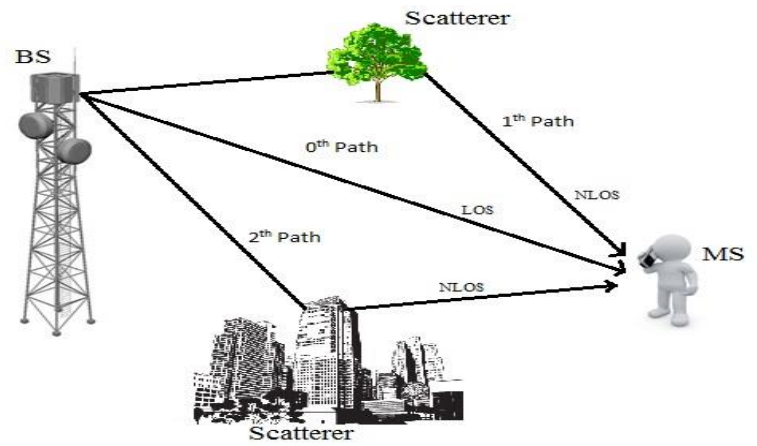

Figure 1. Mobile communication environment (Multipath Propagation)

Direct paths are known as Line of Sight (LOS) and scattered paths are known as Non Line of Sight (NLOS) [6].

\subsubsection{Wireless Propagation and Environmental Model}

A signal from BS comes through a different distance, is subject to attenuation because of free space losses and also distance, delay is different which means the phase that is arise at MS is different [3, 19]. The same transmitted signal arriving at the MS with different path, receiving signals is added up at the MS with different attenuation and different delay, this result either constructive interference or destructive interference [18]. Block diagram of the wireless channel model is shown in Figure 2 .

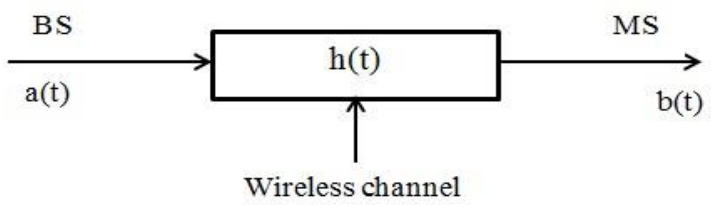

Figure 2. Wireless channel model.

Where a $(\mathrm{t})=$ Signal transmitted by the base station.

$b(t)=$ Signal received from BS through wireless channel.

$h(t)=$ Impulse response of the channel.

System Model:

- The impulse response of the channel is represented as:

$$
h=a_{0} \delta\left(t-\tau_{0}\right)
$$

Where $\mathrm{a}_{0}$ denotes attenuation factor and $\tau_{0}$ denotes delay. The expression of multipath components [27] are represented as:

$$
\begin{gathered}
\mathrm{h} 0=\mathrm{a}_{0} \delta\left(\mathrm{t}-\tau_{0}\right) \rightarrow 0^{\text {th }} \text { Path } \rightarrow \text { LOS } \\
\mathrm{h} 1=\mathrm{a}_{1} \delta\left(\mathrm{t}-\tau_{1}\right) \rightarrow 1^{\text {th }} \text { Path } \rightarrow \text { NLOS } \\
\mathrm{h} 2=\mathrm{a}_{2} \delta\left(\mathrm{t}-\tau_{2}\right) \rightarrow 2^{\text {th }} \text { Path } \rightarrow \text { NLOS } \\
\mathrm{hL}=\mathrm{a}_{\mathrm{L}-1} \delta\left(\mathrm{t}-\tau_{\mathrm{L}-1}\right) \rightarrow \mathrm{L}^{\text {th }} \text { Path } \rightarrow \text { NLOS }
\end{gathered}
$$

Therefore, the wireless channel impulse response $\mathrm{h}(\mathrm{t})$ is expressed as:

$$
h(t)=\sum_{i=0}^{L-1} a_{i}\left(t-\tau_{i}\right)
$$

The transmitted baseband signal from the base station is represented as:

$$
S(t)=\operatorname{Re}\left\{S_{b}(t) e^{j 2 \pi F_{c} t}\right\}
$$

Where $\mathrm{S}(\mathrm{t})=$ Transmitted signal.

$\mathrm{S}_{\mathrm{b}}(\mathrm{t})=$ Complex baseband signal.

$\mathrm{F}_{\mathrm{c}}=$ Carrier frequency.

Here $F_{c}$ denotes carrier frequency and it is important to allocate different carrier frequency to different operators to avoid interference with each other. Before transmits, 
the BS will up convert the BS signal to the allocated carrier frequency and at the MS it will down convert the received signal back to the baseband. Therefore the received signal $y(t)$ is expressed as:

$$
\mathrm{Y}(\mathrm{t})=\mathrm{S}(\mathrm{t}) * \mathrm{~h}(\mathrm{t})
$$

The expression of multipath received signal are represented as:

$$
\begin{aligned}
& 0^{\text {th }} \text { Path } \rightarrow \mathrm{Y}_{0}(\mathrm{t})=\operatorname{Re}\left\{\mathrm{a}_{0} \mathrm{~S}_{\mathrm{b}}\left(\mathrm{t}-\tau_{0}\right) \mathrm{e}^{\mathrm{j} 2 \pi \mathrm{F}_{\mathrm{c}}\left(\mathrm{t}-\tau_{0}\right.}\right\}(9) \\
& 1^{\text {th }} \text { Path } \rightarrow Y_{1}(t)=\operatorname{Re}\left\{a_{1} S_{b}\left(t-\tau_{1}\right) e^{j 2 \pi F_{c}\left(t-\tau_{1}\right.}\right\} \\
& \text { (10) } \\
& 2^{\text {th }} \text { Path } \rightarrow \mathrm{Y}_{2}(\mathrm{t})=\operatorname{Re}\left\{\mathrm{a}_{2} \mathrm{~S}_{\mathrm{b}}\left(\mathrm{t}-\tau_{2}\right) \mathrm{e}^{\mathrm{j} 2 \pi \mathrm{F}_{\mathrm{c}}\left(\mathrm{t}-\tau_{2}\right.}\right\} \\
& \text { (11) } \\
& \mathrm{L}^{\text {th }} \text { Path } \rightarrow \mathrm{Y}_{2}(\mathrm{t})=\operatorname{Re}\left\{\mathrm{a}_{\mathrm{L}-1} \mathrm{~S}_{\mathrm{b}}\left(\mathrm{t}-\tau_{\mathrm{L}-1}\right) \mathrm{e}^{\mathrm{j} 2 \pi \mathrm{F}_{\mathrm{c}}\left(\mathrm{t}-\tau_{\mathrm{L}-1}\right.}\right\}
\end{aligned}
$$

The net signal can be represented as the sum of all signals arriving from the multipath components.

$$
Y(t)=\operatorname{Re}\left\{\left\{\sum_{i=0}^{L-1} a_{i} S_{b}\left(t-\tau_{i}\right) e^{-j 2 \pi F_{c} \tau_{i}}\right\} e^{j 2 \pi F_{c} t}\right\}
$$

Where $e^{-j 2 \pi F_{c} \tau_{i}}$ from equation (13) denotes the complex phase factor.

\subsection{Wireless Communication System Performance}

In a wireless communication system, the performance can be analyzed by Bit Error Rate (BER). BS transmits a stream of 1's and 0's (1101110101) these are coded and transmitted over the wireless channel. At MS, the transmitted signal will be detected or decoded.

$$
\begin{aligned}
& \text { Transmitted bits from BS } \rightarrow 1101110101 \\
& \text { Received bits at MS } \quad \rightarrow 1001110100
\end{aligned}
$$

Receiving bits ( $2^{\text {nd }}$ and $10^{\text {th }}$ bit) contains error information these errors are referred as bit errors. So BER also defined as the probability of getting bit errors in the total information stream.

System model:

The received signal

$$
\mathrm{Y}=\mathrm{hx}+\mathrm{n}
$$

Where $\mathrm{Y}=$ Received signal.

$\mathrm{h}=$ Fading coefficient of channel.

$\mathrm{n}=$ Noise.
Here ' $h$ ' is the fading coefficient of the channel, $h$ can be represented as:

$$
\mathrm{h}=\mathrm{a} \mathrm{e}^{\mathrm{j} \varnothing}
$$

Where a is Rayleigh distribution and $\varnothing$ is uniformly distributed. The transmitted power of the signal can be represented by $\mathrm{P}$ and noise power can be represented by $\sigma_{\mathrm{n}}^{2}$.

$$
\text { Received Power }=\mathrm{P} \times|\mathrm{h}|^{2}=\mathrm{P} \times \mathrm{a}^{2}
$$

Therefore Signal to Noise Ratio (SNR) represented as:

$$
\begin{gathered}
\text { SNR }=\frac{\text { Signal Power }}{\text { Noise Power }} \\
\text { SNR }=\mathrm{a}^{2} \frac{\mathrm{P}}{\sigma_{\mathrm{n}}^{2}}
\end{gathered}
$$

Where $\mathrm{a}=$ Gain of the wireless channel.

$$
\begin{aligned}
& \therefore \text { BER }=Q \sqrt{S N R} \\
& \text { BER }=Q \sqrt{\mathrm{a}^{2} \frac{P}{\sigma_{\mathrm{n}}^{2}}}
\end{aligned}
$$

Here ' $a$ ' is the random quantity because it is a random multipath component. After simplification of the equation (17), the BER can be written as:

$$
\mathrm{BER}=\frac{1}{2}\left(1-\sqrt{\frac{\mathrm{SNR}}{2+\mathrm{SNR}}}\right)
$$

BER of the wireless channel at high SNR is $\frac{1}{2 \mathrm{SNR}}$.

$$
\therefore \mathrm{BER} \approx \frac{1}{2 \mathrm{SNR}}
$$

Case 1:

Compute $\mathrm{SNR}_{\mathrm{dB}}$ of a wireless communication system for $\operatorname{BER}=10^{-6}$.

Compute SNR from the equation (19).

$$
\mathrm{SNR}_{\mathrm{dB}}=57 \mathrm{~dB} \text {. }
$$

As compared with the wire-line communication, wireless communication required more power to achieve less BER. Wireless system has a high BER and poor performance in this case. This is due to fading. In a wireless communication system, it needs a huge amount of power to achieve the lower BER because of the fading nature of the wireless environment. To overcome this problem, the signal should be transmitted at high power. SNR vs BER for digital wired communication and wireless communication system shown in Figure 3. 


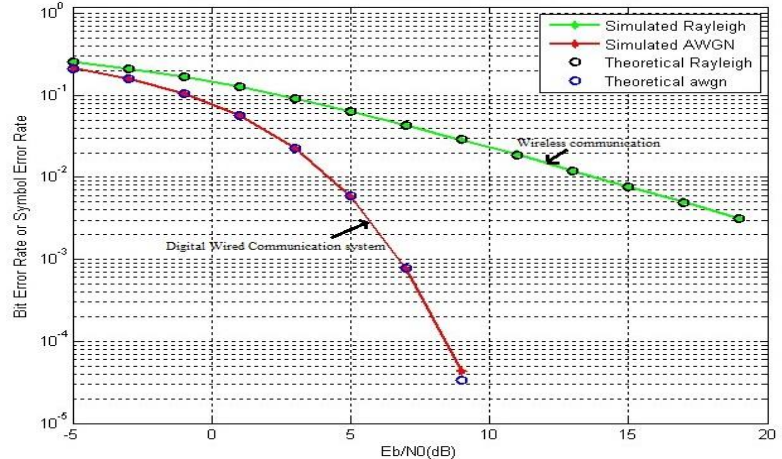

Figure 3. BER vs SNR for AWGN and Rayleigh Channel.

By referring Figure 3 it is concluded that, when the SNR increase BER for digital wired communication drastically decreasing, but BER for wireless communication is very slow rate of decreasing due to the multipath components. The poor performance of wireless communication is arising from 'deep fade' and it arises because of destructive interference.

$$
\begin{aligned}
& \text { The probability of deep fade }=\frac{1}{\text { SNR }} \\
& \therefore \text { BER } \approx \text { Probability of deep fade }
\end{aligned}
$$

This result shows that, in wireless communication the BER is nothing but a deep fade. To improve the performance of wireless communication system through controlling or combating fading environment. This can be done using diversity technique.

\subsection{Diversity and Model}

Diversity is the fundamental technique in $3 \mathrm{G} / 4 \mathrm{G}$ wireless communication system, which will improve the performance of wireless communication through controlling or combating fading environment, How?. Consider there are multiple links between transmitter and receiver, in there multiple links, even one or two links are in deep fade or error, the rest of the links successfully carries the information. This technique is named as diversity [7]. Schematic diagram of a single link and multiple links (Receiver Diversity) is shown in Figure 4 and Figure 5.

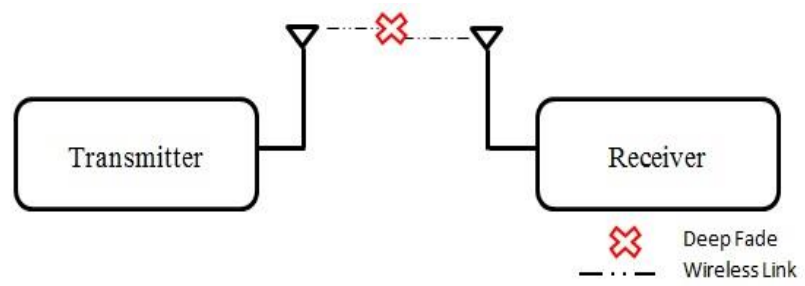

Figure 4. Single Input and Single Output (SISO) system with deep fade.

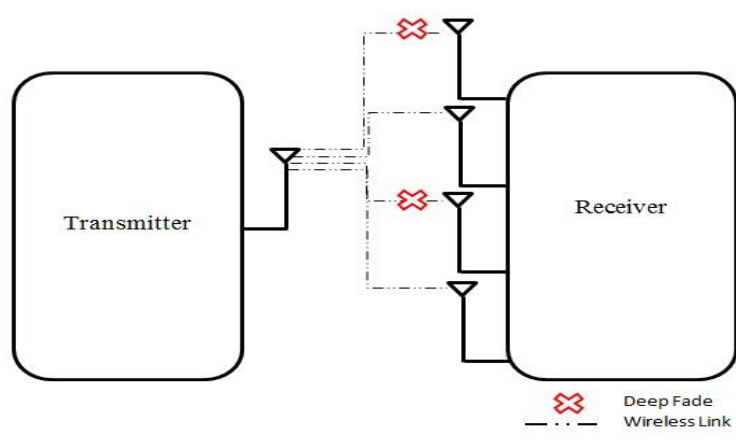

Figure 5. Multiple link system with deep fade.

The multiple link system having multiple links between the transmitter and receiver as compared with the single link system with deep fades. This is only the possible way to improve the performance of wireless communication system.

\subsubsection{Multiple Antenna System and The Model}

In multiple antenna system, $\mathrm{N}$ numbers of antennas are located at the receiver end. In this system, the receiver will be having multiple copies of transmitting signals over different links [20]. The schematic diagram of a multiple antenna system or receive diversity is shown in Figure 6.

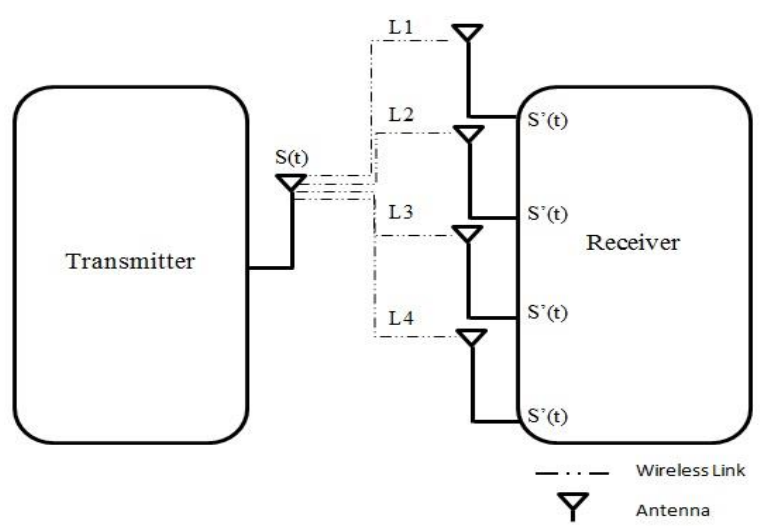

Figure 6. Multiple antenna system (SIMO).

Where, $\mathrm{S}(\mathrm{t})=$ Transmitted signal.

$S^{\prime}(t)=$ Received signal.

$\mathrm{L}=$ Links between Transmitter and Receiver.

If L1 and L2 are in deep fade, then the receiver can recover the transmitted signal through L3 and L4.

System Model:

Consider one transmit antenna and $\mathrm{L}$ receive antenna system this is known as $L^{\text {th }}$ order diversity [27]. Schematic diagram of $L^{\text {th }}$ order receive antenna system shown in Figure 7. 


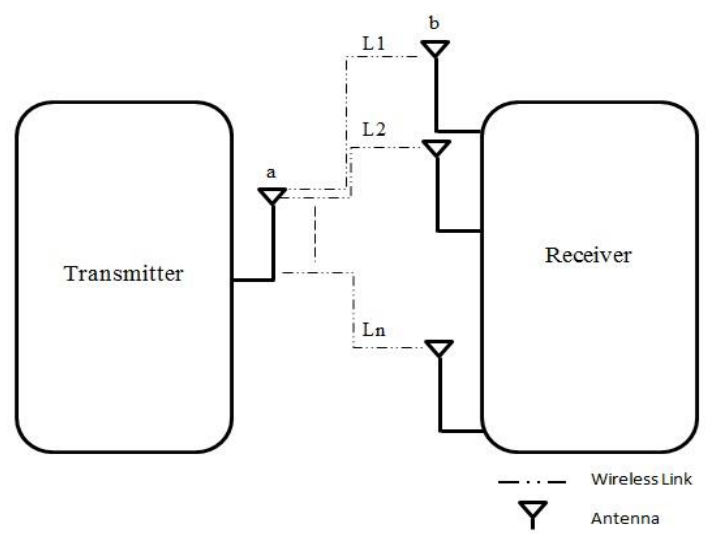

Figure 7. $L^{\text {th }}$ order receive antenna system

Where, $\mathrm{a}=$ Transmitted signal.

$\mathrm{b}=$ Received signal.

$$
\mathrm{b}=\mathrm{ha}+\mathrm{n}
$$

For multiple links:

$$
\begin{aligned}
& b_{1}=h_{1} a+n_{1} \\
& b_{2}=h_{2} a+n_{2} \\
& b_{3}=h_{3} a+n_{3} \\
& b_{L}=h_{L} a+n_{L}
\end{aligned}
$$

Where, $\mathrm{a}=$ Copies of transmitted signal.

$\mathrm{h}_{1}=$ Fading coefficient of wireless channel 1

$\mathrm{h}_{2}=$ Fading coefficient of wireless channel 2

$\mathrm{h}_{3}=$ Fading coefficient of wireless channel 3

$h_{L}=$ Fading coefficient of wireless channel $L$

The system model of multiple antennas can be expressed as:

$$
\begin{gathered}
{\left[\begin{array}{c}
\mathrm{b}_{1} \\
\mathrm{~b}_{2} \\
\mathrm{~b}_{3} \\
: \\
\mathrm{b}_{\mathrm{L}}
\end{array}\right]=\left[\begin{array}{c}
\mathrm{h}_{1} \\
\mathrm{~h}_{2} \\
\mathrm{~h}_{3} \\
: \\
\cdot \\
\mathrm{h}_{\mathrm{L}}
\end{array}\right] \mathrm{a}+\left[\begin{array}{c}
\mathrm{n}_{1} \\
\mathrm{n}_{2} \\
\mathrm{n}_{3} \\
: \\
\cdot \\
\mathrm{n}_{\mathrm{L}}
\end{array}\right]} \\
\therefore \overline{\mathrm{b}}=\overline{\mathrm{h}} \mathrm{a}+\overline{\mathrm{n}}
\end{gathered}
$$

\subsubsection{Analysis of Receive Antenna Diversity System}

Signal detection:

$$
\overline{\mathrm{b}}=\overline{\mathrm{h}} \mathrm{a}+\overline{\mathrm{n}}
$$

Here $h$ is the fading coefficient of channel. The expected value of noise is expressed as:

$$
\mathrm{E}\left\{\left|\mathrm{n}_{\mathrm{i}}(\mathrm{k})\right|^{2}\right\}=\sigma_{\mathrm{n}}^{2}
$$

$b_{1}, b_{2}, b_{3}, \ldots, b_{L}$ are the received signal at $L$ receive antenna. The entire signal will be combined to detect the transmitted signal. The expression for the combined received signal (RS) is:

$$
\mathrm{RS}=\mathrm{W}_{1}^{*} \mathrm{~b}_{1}+\mathrm{W}_{2}^{*} \mathrm{~b}_{2}+\mathrm{W}_{3}^{*} \mathrm{~b}_{3}+. .+\mathrm{W}_{\mathrm{L}}^{*} \mathrm{~b}_{\mathrm{L}}
$$

Here it shows weighing each $\mathrm{b}_{1}$ by $\mathrm{W}_{1}$ and added all received signals. So the received signal is combined linearly and detects the transmitted signal [27]. The combined received signal is expressed as:

$$
\text { Received Signal }=\overline{\mathrm{W}}^{\mathrm{H}} \mathrm{b}
$$

This expression is known as "Beamforming" [27] and $\bar{W}$ is known as "Beamformer". Therefore the beamformer output will be written as:

$$
\begin{gathered}
\text { Beamformer output }=\overline{\mathrm{W}}^{\mathrm{H}} \mathrm{b}=\overline{\mathrm{W}}^{\mathrm{H}}(\overline{\mathrm{h}} \mathrm{a}+\overline{\mathrm{n}})= \\
=\overline{\mathrm{W}}^{\mathrm{H}} \overline{\mathrm{h}} \mathrm{a}+\overline{\mathrm{W}}^{\mathrm{H}} \overline{\mathrm{n}}
\end{gathered}
$$

Where, $\overline{\mathrm{W}}^{\mathrm{H}} \overline{\mathrm{h}} \mathrm{a}=$ Signal component

$$
\overline{\mathrm{W}}^{\mathrm{H}} \overline{\mathrm{n}}=\text { Noise component }
$$

Therefore the signal to noise ratio can be written as:

$$
\begin{gathered}
\text { SNR }=\frac{\left|\overline{\mathrm{W}}^{\mathrm{H}} \overline{\bar{h}}\right|^{2} \mathrm{P}}{\sigma_{\mathrm{n}}^{2} \overline{\mathrm{W}}^{\mathrm{H}} \overline{\mathrm{W}}} \\
\text { Maximize SNR }=\left(\frac{\left|\overline{\mathrm{W}}^{\mathrm{H}} \bar{h}\right|^{2}}{\overline{\mathrm{W}}^{\mathrm{H}} \overline{\mathrm{W}}}\right) \frac{\mathrm{P}}{\sigma_{\mathrm{n}}^{2}}
\end{gathered}
$$

Where $\mathrm{P}=$ Signal power.

$$
\sigma_{\mathrm{n}}^{2}=\text { Noise power. }
$$

To maximize the SNR, choose $\overline{\mathrm{W}}^{\mathrm{H}} \overline{\mathrm{W}}$ value as 1 . Therefore, the SNR is written as:

$$
\mathrm{SNR}=\left|\overline{\mathrm{W}}^{\mathrm{H}} \overline{\mathrm{h}}\right|^{2} \frac{\mathrm{P}}{\sigma_{\mathrm{n}}^{2}}
$$

Where $\bar{W}$ is the optimal beamforming vector. The expression for optimal beamforming is:

$$
\overline{\mathrm{W}}_{\mathrm{opt}}=\frac{\overline{\mathrm{h}}}{\|\overline{\mathrm{h}}\|}
$$

This is known as Maximal Ratio Combiner (MRC) or spatial matching filter. Therefore, the receive SNR after MRC is expressed as: 


$$
\mathrm{SNR}=\|\overline{\mathrm{h}}\|^{2} \frac{\mathrm{P}}{\sigma_{\mathrm{n}}^{2}}
$$

The BER with $\mathrm{L}$ receive antenna after MRC combining is expressed as:

$$
\mathrm{BER}=\left(\frac{1-\lambda}{2}\right)^{\mathrm{L}} \sum_{\mathrm{l}=0}^{\mathrm{L}-1} \mathrm{~L}+\mathrm{l}-1_{\mathrm{C}_{\mathrm{l}}}\left(\frac{1+\lambda}{2}\right)^{\mathrm{L}}
$$

Where $\lambda=\sqrt{\frac{\text { SNR }}{2+\text { SNR }}}$

The BER with $\mathrm{L}$ receive antenna after MRC at high SNR is expressed as:

$$
\mathrm{SNR}=2 \mathrm{~L}-1_{\mathrm{C}_{\mathrm{L}}}\left(\frac{1}{\mathrm{SNR}}\right)^{2}
$$

Case 2:

Consider two antennas at the receiver, compute the SNR in $\mathrm{dB}$ for $\mathrm{BER}=10^{-6}$ in a wireless communication system. By using equation (35), the computed $\mathrm{SNR}_{\mathrm{dB}}=29.37 \mathrm{~dB}$.

As compared with the single antenna system $\left(\mathrm{SNR}_{\mathrm{dB}}=57\right.$ $\mathrm{dB})$, it requires less power at the receiver to recover the signal. Adding one antenna results in significant improvement in the BER at receiver. As the number of receive antenna keep increasing progressively, the BER keep decreasing fast rate and it improves the performance of the system. The BER vs SNR with receive diversity is shown in Figure 8.

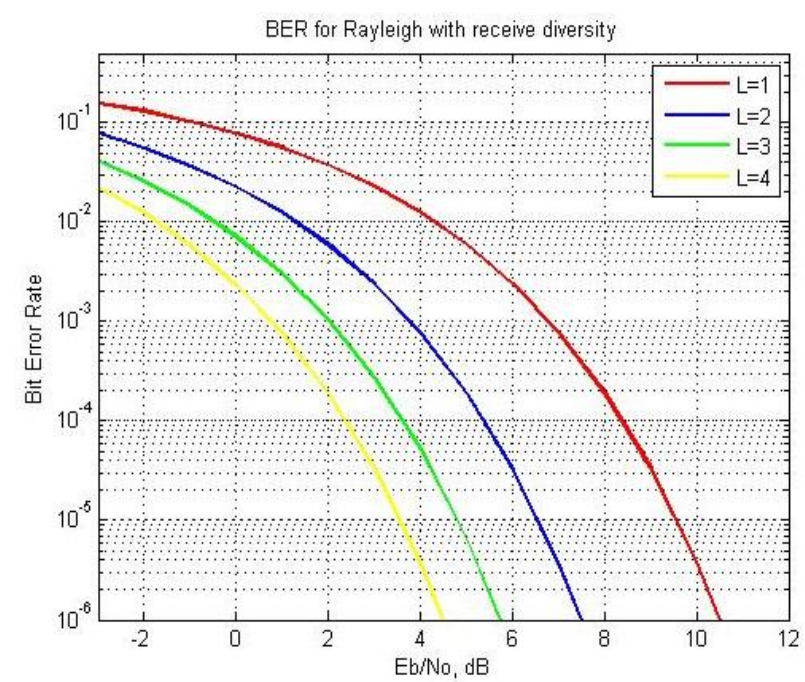

Figure 8. BER vs SNR for $\mathrm{L}$ receive antenna diversity

Hence receive diversity is very important in $3 \mathrm{G} / 4 \mathrm{G}$ wireless communication system. It is employed in many technologies like Wideband CDMA (WCDMA), High
Speed Downlink Packet Access (HSDPA), High Speed Uplink Packet Access (HSUPA) and WiMaX.

\subsection{Coherence Bandwidth and Delay Spread}

Coherence bandwidth: The portion of spectrum over which the response is approximately constant or flat [3]. Consider a system,

$\mathrm{X}(\mathrm{f})=$ Transmitted signal from BS.

$\mathrm{H}(\mathrm{f})=$ Wireless response of the channel.

$\mathrm{Y}(\mathrm{f})=$ Received signal.

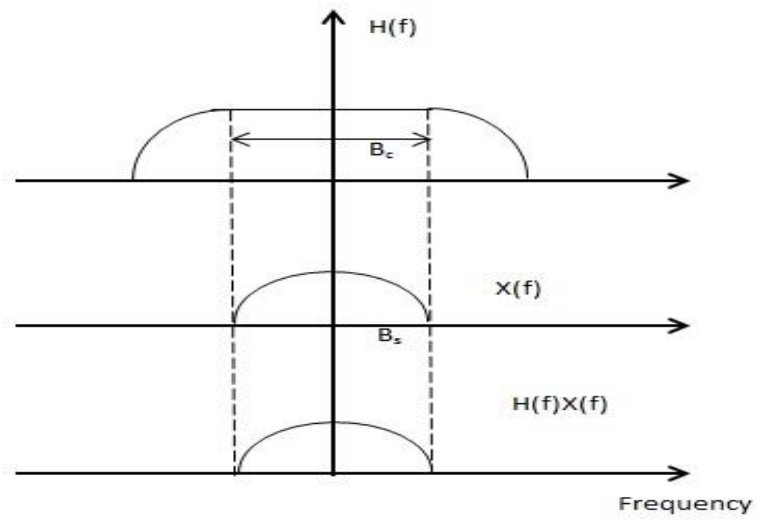

Figure 9. Coherence bandwidth

Where, $\mathrm{B}_{\mathrm{C}}=$ Coherence bandwidth.

$\mathrm{B}_{\mathrm{S}}=$ Signal bandwidth

If the coherence bandwidth is greater than signal bandwidth, then there is no distortion in the received signal because the input signal is scaled by the constant or flat value. This is known as flat fading channel. If the signal bandwidth is greater the coherence bandwidth, then there will be a distortion in the received signal. This is known as frequency selective distortion. This frequency selective fading will affect the performance of wireless communication system. To avoid this, some technique has to employ at the receiver to reverse this distortion. This is known as equalization technique [8].

Delay spread: Multiple signal copies are arriving at receiver over an interval of time. This time spread or time interval is termed as delay spread. Pictorial representation of delay spread is shown in Figure 10. 


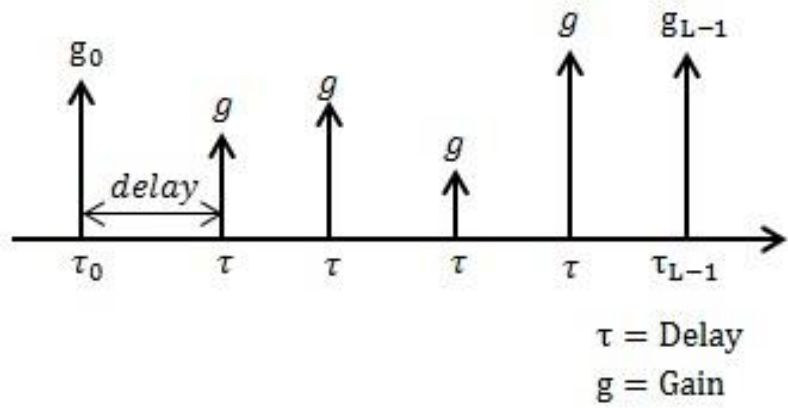

Figure 10. Delay spread

The outdoor delay spread in $3 \mathrm{G} / 4 \mathrm{G}$ wireless communication system is approximately of the order of 1$3 \mu \mathrm{s}$ and indoor delay spread are 10-50 ns.

\section{CDMA/3G TECHNOLOGY}

Code Division Multiple Access (CDMA) is a multiple access technology; it will transmit multiple information to multiple users using the same channel, how? CDMA is one of the techniques which enables multiple access by using different codes corresponding to different users over the common channel $[2,9]$. The present $3 \mathrm{G}$ system based on CDMA namely WCDMA, HSDPA-HSUPA and CDMA 2000.

\subsection{Multiple Access}

Consider a Base Station (BS) which transmitting signal to user 0 and user 1 . For both the users there is no separate channel, unlike in digital wired communication, there has to be a way of transmitting independent information to each of the users to access the BS. By correlating the different codes corresponding to different users, can able to recover the signal [9]. The schematic diagram of multiple access is shown in Figure 11.

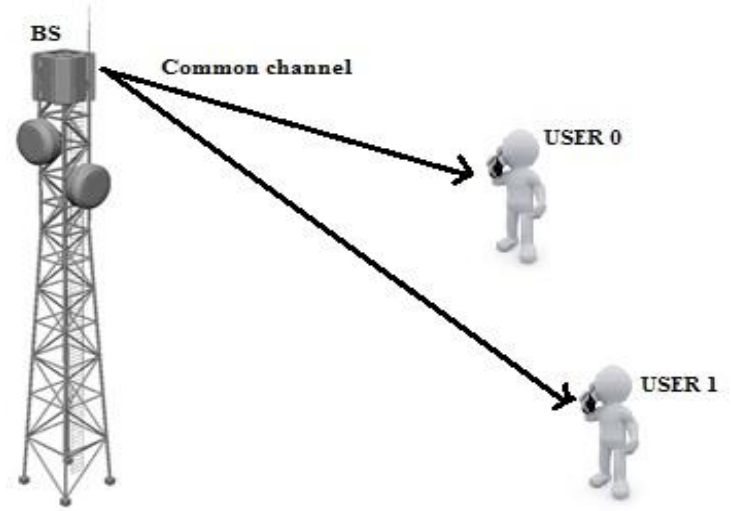

Figure 11. Multiple Access CDMA

Consider $\mathrm{a}_{0}$ is the transmitting information for user 0 and $\mathrm{a}_{1}$ is the transmitting information for user 1 , from BS. The code for user 0 is [ [ $\left.\begin{array}{llll}1 & 1 & 1 & 1\end{array}\right]$ and code for user 1 is [ $\left[\begin{array}{lll}1 & -1 & -1\end{array}\right.$ 1]. In the next step, the codes assigned for user 0 and user 1 , will be multiplied with information of the respective users. The result of the multiplication is:

$$
\begin{gathered}
\text { User } 0 \rightarrow\left[a_{0}, a_{0}, a_{0}, a_{0}\right] \\
\text { User } 1 \rightarrow\left[a_{1},-a_{1},-a_{1}, a_{1}\right]
\end{gathered}
$$

The addition of user 0 and user 1 will produce the transmitting net signal as represented as:

$$
a_{0}+a_{1}, a_{0}-a_{1}, a_{0}-a_{1}, a_{0}+a_{1}
$$

At Receiver:

The transmitted signal over the channel will be expressed as:

$$
\mathrm{Tx} \rightarrow\left(\mathrm{a}_{0}+\mathrm{a}_{1}, \mathrm{a}_{0}-\mathrm{a}_{1}, \mathrm{a}_{0}-\mathrm{a}_{1}, \mathrm{a}_{0}+\mathrm{a}_{1}\right)
$$

The received signal will be expressed as:

$$
\mathrm{Rx} \rightarrow\left(\mathrm{a}_{0}+\mathrm{a}_{1}, \mathrm{a}_{0}-\mathrm{a}_{1}, \mathrm{a}_{0}-\mathrm{a}_{1}, \mathrm{a}_{0}+\mathrm{a}_{1}\right)+\text { Noise }
$$

To extract the information signal of user 0 , correlating the

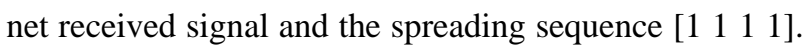
The result will be expressed as:

$$
\begin{gathered}
\rightarrow\left(a_{0}+a_{1}\right)+\left(a_{0}-a_{1}\right)+\left(a_{0}-a_{1}\right)+\left(a_{0}+a_{1}\right) \\
=4 a_{0}
\end{gathered}
$$

Similarly to extract the information signal of user 1, correlating the net received signal and the spreading

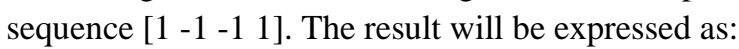

$$
\begin{gathered}
\rightarrow\left(a_{0}+a_{1}\right)-\left(a_{0}-a_{1}\right)-\left(a_{0}-a_{1}\right)+\left(a_{0}+a_{1}\right) \\
=4 a_{1}
\end{gathered}
$$

Hence, by correlating the different codes corresponding to the different users can able to recover the signal of both user 0 and user 1 . The spreading codes will spread the bandwidth of the original signal So CDMA named as spread spectrum technology. Bandwidth spreads by a factor of ' $N$ ' (Spreading factor), which is the length of the spreading sequence,

If $\mathrm{N}=4$ then it will support 4 users, if $\mathrm{N}=16$ then it will support 16 users and if $\mathrm{N}=2^{10}$ then it will support 1024 users. The maximum length sequence can be achieved by Linear Feedback Shift Registers (LFSR). The signal to noise ratio for multiuser CDMA is:

$$
\mathrm{SNR}=\frac{\mathrm{P}_{0} \cdot \mathrm{N}}{\mathrm{P}_{1}+\sigma_{\mathrm{w}}^{2}}
$$


Where, $\mathrm{P}_{0}=$ Signal power.

$\mathrm{P}_{1}=$ Multiuser interference.

$\sigma_{\mathrm{w}}^{2}=$ Noise component.

$\mathrm{N}=$ Spreading gain

CDMA typically having the very low transmitting power because the receiver is having gain and also it's having wider bandwidth. Some of the $3 \mathrm{G}$ applications are GPS, location based service, mobile TV, telemedicine and cellular communication [10].

\section{TECHNOLOGY DEPLOYED FOR 4G}

$4 \mathrm{G}$ is the fourth generation of cellular communication technology, succeeding 3G. In 2008, International Telecommunication Union (ITU) assigned a set of 4G standard requirements, named International Mobile Telecommunications (IMT-advanced) specifications. 100 Mbps for high mobility service and 1Gbps for low mobility service. The current popular $4 \mathrm{G}$ technology is LTE standard was first proposed by Nippon Telegraph and Telephone (NTT) Docomo of japan and commercial service for 4G started in Sweden and Norvey in 2009 [11]. LTE technology was globally adopted 2010. Technologies deployed in 4G are LTE standard, LTE advanced, OFDMA, 3GPP LTE, Wimax and MC-CDMA. Some of the technologies explained here.

\subsection{LTE Standard}

In today's cellular communication market LTE is playing a vital role all over the world. Number of users are adopted to this 4G LTE technology and also getting higher data rate, QoS, improved spectral efficiency and reduced cost of backhaul [12]. The LTE operates in both Time Division Duplex (TDD) and Frequency Division Duplex (FDD) modes and many frequency bands used for LTE TDD and FDD standards. Frequency bands for 4G LTE system vary according to the countries. Some frequency bands adopted for this LTE FDD system are $2100 \mathrm{MHz}, 1900 \mathrm{MHz}, 1800 \mathrm{MHz}, 1700 \mathrm{MHz}, 2600$ $\mathrm{MHz}$, and $3500 \mathrm{MHz}$. TDD LTE frequency bands are $2100 \mathrm{MHz}, 1900 \mathrm{MHz}, 2600 \mathrm{MHz}, 3500 \mathrm{MHz}, 3700$ $\mathrm{MHz}, 700 \mathrm{MHz}, 1500 \mathrm{MHz}, 5200 \mathrm{MHz}$ and $5900 \mathrm{MHz}$. In India (Asia) the service providers of 4G LTE are Jio, Airtel, Vodafone, Aircel, BSNL and Idea. Some popular bands used in India are FDD $850 \mathrm{MHz}$, TDD $2300 \mathrm{MHz}$, FDD $1800 \mathrm{MHz}$ and TDD $2500 \mathrm{MHz}$. This LTE technology dominates broadband access; day by day number of subscribers are increasing in cellular technology as compared with a fixed line.

\subsection{LTE Advanced}

LTE advanced technology is the enhanced version of the LTE standard. This system was submitted by 3 GPP to ITU-T in 2009, the main focus of this advanced technology is to provide spectral efficiency up to 3 bits $/ \mathrm{s} / \mathrm{Hz} /$ cell in downlink and $2.25 \mathrm{bits} / \mathrm{s} / \mathrm{Hz} / \mathrm{cell}$ for indoor communication, high Quality of Service (QoS), scalable channel bandwidth up to $40 \mathrm{MHz}$ and interoperability with existing standards. LTE advanced technology will be the next generation cellular networks and which is having higher standards and improved technologies as compared with the current LTE standard [13]. In current LTE standard, the requirements set by the ITU are not up to that mark, so this leads to the LTE advanced standards. This is based on internet protocol packet switched network and it will provide scalable channel bandwidth. This technology promises to support $3 \mathrm{Gbps}$ for fixed communication and also it will provide proper handoff between cells. In future LTE-A might be named as a $5^{\text {th }}$ generation network [14].

\subsection{GPP LTE Standard}

3GPP is the telecommunication body associate with ITU to develop 3G mobile standard globally. The partners of 3GPP are ARIB (Japan), CCSA (China), ETSI (Europe), TSDSI (India), TTA (Korea), ATIS (USA) and TTC (Japan). The aim of this body later enlarged to maintained and development of GSM (2G), UMTS (3G), LTE (4G), LTE advanced, LTE advanced Pro, Next generation cellular network (5G) and IMS (IP multimedia subsystem). 3GPP standards are structured as releases, the $1^{\text {st }}$ 3GPP LTE released in $2008\left(\mathrm{R}_{8}\right)$ and MIMO also plays major role in the current 4G LTE system [15].

\subsection{WIMAX Technology}

Worldwide Interoperability for Microwave Access (WIMAX) is the broadband wireless technology for point to multipoint access, which enables high data rate and QoS, by using OFDM and MIMO techniques [16]. The first WIMAX service was started by the KT corporation in 2006 (South Korea, Seoul) [17]. It is branded as fourth generation wireless network with a speed of $128 \mathrm{Mbps}$. This technology also adopted in china market as 4G, due to lack speed as compared with 4G LTE standard and IMT advanced requirements, it has not come up to the mark. A lot of researchers are working to improve WIMAX technology and to fulfill the IMT advanced requirements in future. 


\subsection{OFDM Technology}

Orthogonal Frequency Division Multiplexing (OFDM) is the method of transmitting digital information over multiple carriers. Each subcarrier is orthogonal to each other to avoid the interference. The main advantage this technology is free from frequency selective fading and Inter-symbol interference. This technique adopted in current 4G LTE standard and WIMAX standard to improve the data rate [18].

\subsubsection{Multicarrier Transmission Scheme}

OFDM is a multicarrier modulation technique which will divide full carrier into a number of subcarriers, which means dividing wider bandwidth into small limited narrow bandwidth. Consider signal bandwidth $\mathrm{B}=256$ $\mathrm{KHz}$, number of subcarrier $\mathrm{N}=64$, then the bandwidth for each subcarrier is $\frac{\mathrm{B}}{\mathrm{N}}=4 \mathrm{KHz}$, so it will experience frequency flat fading [3] because the subcarrier bandwidth is lesser than the coherence bandwidth $\left(\mathrm{B}_{\mathrm{c}} \cong\right.$ 200 to $300 \mathrm{KHz}$ ) [3].

Model:

Consider the center frequency of $i^{\text {th }}$ subcarrier is:

$$
\mathrm{F}_{\mathrm{i}}=\mathrm{i} \frac{\mathrm{B}}{\mathrm{N}} \quad-\left(\frac{\mathrm{N}}{2}-1\right) \leq \mathrm{i} \leq \frac{\mathrm{N}}{2}
$$

The multicarrier composite transmitted signal is expressed as:

$$
U(t)=\sum_{i} a_{i} e^{j 2 \pi i \frac{B}{N} t}
$$

Where $\mathrm{U}(\mathrm{t})=$ Transmitted multicarrier signal.

$\mathrm{a}_{\mathrm{i}}=$ Data transmitted on $\mathrm{i}^{\text {th }}$ subcarrier.

$\mathrm{i} \frac{\mathrm{B}}{\mathrm{N}}=\mathrm{F}_{\mathrm{i}}=$ Center frequency.

Multicarrier data detection:

The received signal is expressed as:

$$
v(t)=U(t)=\sum_{i} a_{i} e^{j 2 \pi i \frac{B}{N} t}
$$

Correlate $\mathrm{v}(\mathrm{t})$ with the exponential term and take conjugate,

$$
\rightarrow v(t)\left(e^{i 2 \pi F_{i} t}\right)^{*}
$$

After simplification, demodulation with $1^{\text {th }}$ coherent subcarrier result will be expressed as:

$$
\frac{\mathrm{B}}{\mathrm{N}} \times \mathrm{a}_{\mathrm{i}} \times \frac{\mathrm{N}}{\mathrm{B}}=\mathrm{a}_{\mathrm{i}}
$$

Hence $a_{i}$ is recovered by coherently demodulating with $\mathrm{e}^{\mathrm{j} 2 \pi \mathrm{i} \frac{\mathrm{B}}{\mathrm{N}} \mathrm{t}}$. So above scheme is termed as Multicarrier Modulation (MCM) method and this is the basic for OFDM technique.

\subsubsection{OFDM Model}

In the multicarrier modulation technique $i^{\text {th }}$ number of data streams is modulated on $\mathrm{i}^{\text {th }}$ number of subcarriers, by using an $\mathrm{N}$ number of modulators. The all modulated signals will be converted into serial form which is known as composite signal, this will be transmitted to the channel. But the particular concept is not practically possible because of the complexity. So instead of using modulators and demodulators, the same results can be generated by employing Inverse Fast Fourier Transform (IFFT) and Fast Fourier Transform (FFT) operations at transmitter and receiver side respectively [3, 18] This particular concept is known as OFDM, which will reduce the complexity to implement and this whole process can be integrated on a Digital Signal Processor (DSP) chip to perform a fast operation [19]. The schematic diagram of MCM transmitter and receiver [3] is shown in Figure 12 and the schematic diagram of OFDM transmitter and receiver $[3,19]$ is shown in Figure 13.

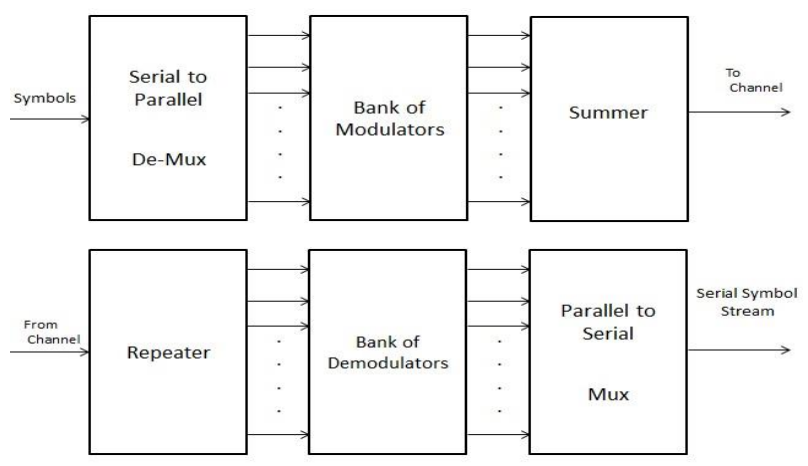

Figure 12. MCM transmitter and receiver
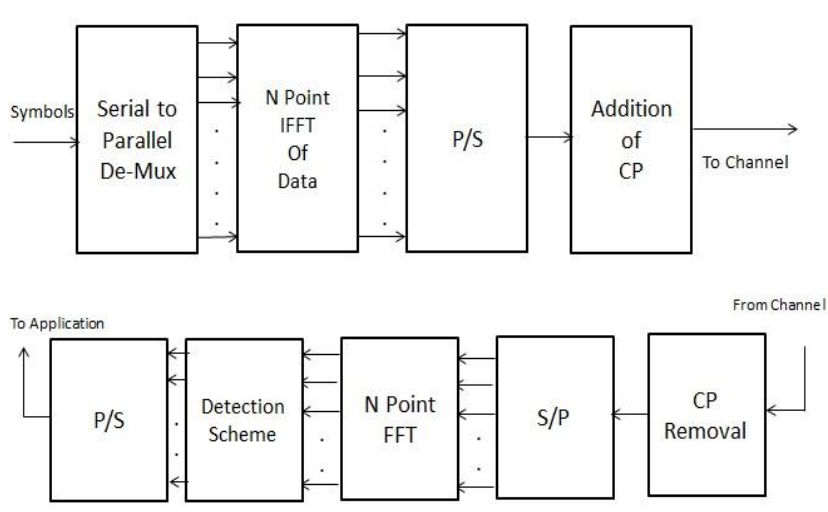

Figure 13. OFDM transmitter and receiver 
The message symbols are written as:

$$
\text { Symbols }=\mathrm{m}(0) \mathrm{m}(1) \mathrm{m}(2) \ldots \ldots . . \mathrm{m}(\mathrm{N}-1)(40)
$$

The serial form of message symbols will be converted to parallel because to modulate carrier according to the information signal. IFFT will be applied to the symbols [3], the expression after IFFT is written as:

$$
\text { After IFFT }=\mathrm{M}(0) \mathrm{M}(1) \mathrm{M}(2) \ldots \ldots . \mathrm{M}(\mathrm{N}-1)(41)
$$

This expression corresponds to IFFT of the equation (40). After the IFFT operation, the parallel form of signal converted to serial and adding Cyclic Prefix (CP) [19] to each of the symbols to avoid the interference between the symbols. OFDM symbols without $\mathrm{CP}$ expression as expressed as:

$$
\begin{aligned}
& \breve{M}(0) \bar{M}(1) \breve{M}(2) \ldots \breve{M}(N-2) \breve{M}(N \\
& -1) M(0) M(1) M(2) \ldots M(N-1)
\end{aligned}
$$

Where $\breve{M}$ denotes previous OFDM symbol and M denotes current OFDM symbol.

This OFDM without a CP composite signal can be transmitted over the channel. The multipath frequency selective channel can be modeled as:

$$
\mathrm{h}(0) \mathrm{h}(1) \mathrm{h}(2) \ldots \ldots \ldots \ldots \ldots \mathrm{h}(\mathrm{L}-1)
$$

The received signal $\mathrm{y}(0) \mathrm{y}(1) \mathrm{y}(2) \ldots \ldots \ldots \ldots \mathrm{y}(\mathrm{N}-1)$ can be resulted as:

$$
\begin{gathered}
\mathrm{y}(0)=\mathrm{h}(0) \mathrm{M}(0)+\mathrm{h}(1) \overline{\mathrm{M}}(\mathrm{N}-1)+\mathrm{h}(2) \overline{\mathrm{M}}(\mathrm{N}-2) \\
+\cdots+\mathrm{h}(\mathrm{L}-1) \overline{\mathrm{M}}(\mathrm{N}-\mathrm{L}+1) \\
\mathrm{y}(1)=\mathrm{h}(0) \mathrm{M}(1)+\mathrm{h}(1) \mathrm{M}(0)+\mathrm{h}(2) \overline{\mathrm{M}}(\mathrm{N}-1)+\cdots \\
+\mathrm{h}(\mathrm{L}-1) \overline{\mathrm{M}}(\mathrm{N}-\mathrm{L}+2)
\end{gathered}
$$

The above OFDM without CP signal is much larger, it consists of $\mathrm{N}$ number of samples, and however they still have ISI in initial parts. The solution to overcome from this Inter-Symbol Interference (ISI), CP has to be inserted between the symbols. Now the OFDM with CP symbols will be looks like,

$$
\begin{gathered}
\text { OFDM with } \mathrm{CP}=\mathrm{M}(\mathrm{N}-\mathrm{L}+1) \ldots \ldots \ldots \mathrm{M}(\mathrm{N}-2) \\
\qquad(\mathrm{N}-1) \mathrm{M}(0) \mathrm{M}(1) \ldots \ldots \mathrm{M}(\mathrm{N}-1)
\end{gathered}
$$

Here all the samples belongs to current OFDM symbols, OFDM with CP expressed as equation (44) and the received signal can be written as:

$$
\begin{gathered}
y(0)=h(0) M(0)+h(1) M(N-1)+h(2) M(N-2) \\
\ldots+h(L-1) M(N-L+1) \\
y(1)=h(0) M(1)+h(1) M(0)+h(2) M(N-1)+\cdots \\
+h(L-1) M(N-L+2)
\end{gathered}
$$

Therefore

$$
\begin{gathered}
\mathrm{y}(\mathrm{N}-1)=\mathrm{h}(0) \mathrm{M}(\mathrm{N}-1)+\mathrm{h}(1) \mathrm{M}(\mathrm{N}-2)+\cdots+ \\
\mathrm{h}(\mathrm{L}-1) \mathrm{M}(\mathrm{N}-\mathrm{L})
\end{gathered}
$$

Therefore the net received signal is expressed as:

$$
\begin{gathered}
{[\mathrm{y}(0) \mathrm{y}(1) \ldots \mathrm{y}(\mathrm{N}-1)]=} \\
=[\mathrm{h}(0) \mathrm{h}(1) \ldots . \mathrm{h}(\mathrm{L}-1)] *[\mathrm{M}(0) \mathrm{M}(1) \ldots . \mathrm{M}(\mathrm{N}-1)] \\
\Rightarrow \mathrm{Y}(\mathrm{k})=\mathrm{H}(\mathrm{k}) * \mathrm{M}(\mathrm{k})
\end{gathered}
$$

Where $\mathrm{Y}(\mathrm{k})=$ Received output across $\mathrm{k}^{\mathrm{th}}$ subcarrier.

$\mathrm{H}(\mathrm{k})=$ Channel coefficient of $\mathrm{k}^{\mathrm{th}}$ subcarrier.

$\mathrm{M}(\mathrm{k})=$ Symbol loaded onto $\mathrm{k}^{\mathrm{th}}$ subcarrier.

Hence, the frequency selective channels are converted into a group of narrow band flat fading channels, this is the advantage of multicarrier modulation system [18]. Also can say wideband/Broadband channel (B) is converted into $\mathrm{N}$ narrow band channels $(\mathrm{B} / \mathrm{N})$, experiences flat fading (No ISI). In fact $\mathrm{CP}$ should be greater than the delay spread of the channel. It creates a loss in spectral efficiency because of repeating the same symbols [19]. Hence the effect of addition of long CP is a loss in throughput of the system.

$$
\begin{gathered}
\text { Loss in efficiency }=\frac{\text { Cyclic prefic length }}{\text { Total OFDM symbol length }} \\
\text { Loss in efficiency }=\frac{\mathrm{L}-1}{\mathrm{~N}+\mathrm{L}-1}
\end{gathered}
$$

Where $\mathrm{N}=$ Symbol length.

$$
\mathrm{L}=\mathrm{CP} \text { length. }
$$

If $\mathrm{N} \Rightarrow \infty$,

$$
\Rightarrow \lim _{\mathrm{N} \rightarrow \infty} \frac{\mathrm{L}-1}{\mathrm{~N}+\mathrm{L}-1}=0
$$

Here, loss in spectral efficiency approaches zero. Hence, a large number of subcarriers implies lower loss of system throughput. After increasing N, results in an increase in OFDM symbol time.

\subsection{MIMO Technology}

The Multiple Input Multiple Output (MIMO) is also referred as multipath propagation system in which, the system will be having more number of antennas at both transmitter and receiver sides. MIMO can increase the data rate by transmitting several information streams in 
parallel with same transmit power. The main focus of MIMO is to use a number of antennas to achieve high speed, more SNR by beamforming and low error rate [20]. In MIMO, most importantly the placement of antennas will be crucial, as this will be known as spatial multiplexing. What will be the crucial part in MIMO? The separation of antennas in such manner that the signal should not interfere with each other [20, 21]. The schematic diagram of MIMO model is shown in Figure 14.

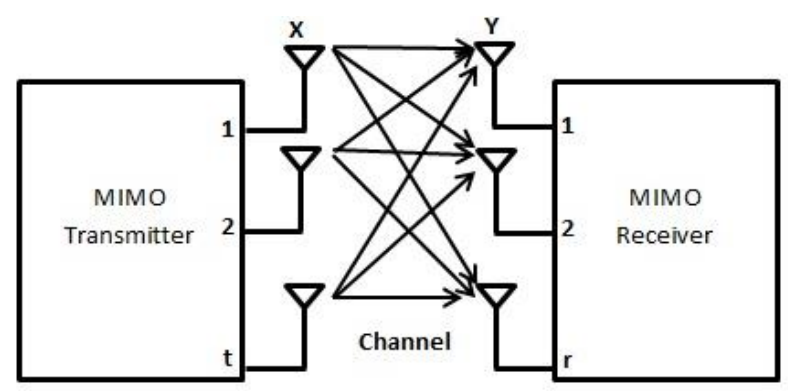

Figure 14. MIMO Model

\subsubsection{MIMO Model}

The transmitted symbols are expressed as:

$$
X=x_{1}, x_{2}, x_{3}, x_{4}, \ldots \ldots \ldots \ldots x_{t}
$$

The received symbols can be expressed as:

$$
\mathrm{Y}=\mathrm{y}_{1}, \mathrm{y}_{2}, \mathrm{y}_{3}, \mathrm{y}_{4}, \ldots \ldots \ldots \ldots \mathrm{y}_{\mathrm{r}}
$$

The channel for MIMO can be modeled as:

$$
H=\left[\begin{array}{ccc}
h_{11} & h_{12} & \ldots \ldots \ldots . h_{1 t} \\
h_{21} & h_{22} & \ldots \ldots \ldots . h_{23} \\
\cdot & \cdot & \cdot \\
\cdot & \cdot & \cdot \\
\vdots & \vdots & \vdots \\
h_{r 1} & h_{r 2} & \ldots \ldots \ldots \ldots h_{r t}
\end{array}\right]
$$

The simplified model for MIMO can be expressed [27] as:

$$
\bar{Y}=H \bar{X}+\bar{N}
$$

Here $\mathrm{h}_{\mathrm{rt}}$ is the channel co-efficient between the $\mathrm{r}^{\text {th }}$ receive antenna and $\mathrm{t}^{\text {th }}$ transmit antenna.

Special cases:

If $\mathrm{t}=1$,

$$
\bar{Y}=\bar{h} x+\bar{N}
$$

This particular system is referred as receive diversity. This system is also known as Single Input Multiple Output (SIMO) [27].
If $r=1$,

$$
\overline{\mathrm{Y}}=\overline{\mathrm{h}}^{\mathrm{T}} \overline{\mathrm{X}}+\mathrm{N}
$$

This particular system is referred as transmit diversity. This system is also termed as Multiple Input Single Output (MISO).

If $\mathrm{r}=1$ and $\mathrm{t}=1$,

$$
y=h x+N
$$

This system is known as Single Input Single Output (SISO).

\subsubsection{MIMO Receiver}

To estimate the information signal from MIMO channel, there are lots of MIMO receiver techniques are adopted. Zero forcing is one of the estimators in MIMO receiver, but it results in noise amplification, another popular receiver is known as MIMO-MMSE (Minimum Mean Squared Error) receiver [20], which is robust to noise enhancement [22]. The MMSE is the minimum mean square error receiver, which treats a transmit symbol vector $\bar{X}$ as the random quantity and receive vector $\bar{Y}$ as also a random quantity, that minimize the error in the mean, the MMSE estimator for MIMO can be written as:

$$
\overline{\mathrm{C}}=\mathrm{R}_{\mathrm{yy}}^{-1} \mathrm{R}_{\mathrm{yx}}
$$

Where $R_{y y}=P_{d} H H^{H}+\sigma_{n}^{2} I=$ Covariance matrix of $y$.

$$
\begin{aligned}
\mathrm{R}_{\mathrm{yx}} & =\mathrm{P}_{\mathrm{d}} \mathrm{H} \\
\sigma_{\mathrm{n}}^{2} & =\text { Noise variance. } \\
\mathrm{P}_{\mathrm{d}} & =\text { Transmitter power. }
\end{aligned}
$$

Therefore, $\overline{\mathrm{C}}=\left(\mathrm{P}_{\mathrm{d}} \mathrm{HH}^{\mathrm{H}}+\sigma_{\mathrm{n}}^{2} \mathrm{I}\right)^{-1} \mathrm{P}_{\mathrm{d}} \mathrm{H}$

The basic linear estimator of transmitter signal [20] can be written as:

$$
\widehat{X}=\overline{\mathrm{C}}^{\mathrm{T}} \mathrm{Y}
$$

After simplification $\widehat{\mathrm{X}}$ can be written as:

$$
\widehat{\mathrm{X}}=\frac{\mathrm{P}_{\mathrm{d}} \mathrm{h}^{*}}{\sigma_{\mathrm{n}}^{2}} \overline{\mathrm{Y}}
$$

From this result, MIMO-MMSE estimator does not result in noise enhancement. The SNR of $i^{\text {th }}$ parallel channel MIMO can be written as:

$$
\operatorname{SNR}=\frac{\sigma_{i}^{2} P_{i}}{\sigma_{n}^{2}}
$$

Where $\sigma_{i}^{2}=$ Gain of the channel.

$P_{i}=$ Power allocated to the $i^{\text {th }}$ channel. 


$$
\sigma_{\mathrm{n}}^{2}=\text { Noise power. }
$$

The capacity of $i^{\text {th }}$ parallel channel MIMO can be calculated by Shannon capacity.

$$
\begin{gathered}
\text { Maximum Rate }=\text { Shannon capacity }=\log _{2}(1+\mathrm{SNR}) \\
=\log _{2}\left(1+\frac{\sigma_{\mathrm{i}}^{2} \mathrm{P}_{\mathrm{i}}}{\sigma_{\mathrm{n}}^{2}}\right) \\
\text { Capacity of } 1^{\text {st }} \text { channel }=\log _{2}\left(1+\frac{\sigma_{1}^{2} \mathrm{P}_{1}}{\sigma_{\mathrm{n}}^{2}}\right)=\mathrm{C}_{1} \\
\text { Capacity of } 2^{\text {st }} \text { channel }=\log _{2}\left(1+\frac{\sigma_{2}^{2} \mathrm{P}_{2}}{\sigma_{\mathrm{n}}^{2}}\right)=\mathrm{C}_{2}
\end{gathered}
$$

Hence the total MIMO capacity can be written as:

$$
\text { Total MIMO capacity }=\sum_{\mathrm{i}=1}^{\mathrm{t}} \log _{2}\left(1+\frac{\sigma_{\mathrm{i}}^{2} \mathrm{P}_{\mathrm{i}}}{\sigma_{\mathrm{n}}^{2}}\right)
$$

In MIMO system, the capacity is increasing linearly with respect to same transmit power.

$$
C=\operatorname{Min}(r, t) \log _{2}\left(1+\frac{P_{t}}{\sigma_{n}^{2}}\right)
$$

Suppose, if the transmit antennas are 10 and receive antennas are 4, the capacity will be increased by four times with same transmit power. This shows MIMO system can achieve gains in capacity, which is the key part of $3 \mathrm{G} / 4 \mathrm{G}$ mobile communication. MIMO-OFDM [20] is the another advanced technology for $4 \mathrm{G}$ and it is the foundation for advanced technologies like 4G LTE and 5G. In this technology, the MIMO is integrated with OFDM technique to achieve the enormous throughput and capacity. It converts a MIMO frequency selective channel into a set of multiple parallel flat fading MIMO channel.

\section{5G TECHNOLOGY}

$5 \mathrm{G}$ stands for fifth generation mobile network; it will be the future generation mobile communication standard. Due to the drastic increase of data traffic and convergence of users, the emerging $5 \mathrm{G}$ technology $[1,23]$ has come into the picture. The main challenges in $5 \mathrm{G}$ technologies are accommodating more number of users (100 billion devices), direct to direct communication and massive machine communications. ITU has targeted to implement 5G mobile networks on or after 2020 with the speed of $100 \mathrm{~GB} / \mathrm{s}$ to each user and support 1000 times gain in capacity [4]. Also the focus is on to utilize the widely available spectrum properly. The important topics related to the $5 \mathrm{G}$ communication system are discussed in the following sections.

\subsection{Spectrum for $5 \mathrm{G}$}

In mobile communication, spectrum is one of the important factors. Now a day the consumption of the spectrum is more because of usage of more number of devices. The spectrums which are used for $2 \mathrm{G} / 3 \mathrm{G} / 4 \mathrm{G}$ vary according to the country [24]. A lot of spectrum studies for 5G are conducted by many telecom organizations like RCC, ATU, APT, ASMC, CITL, CEPT and so on. According to IMT research study, low frequency bands below $6 \mathrm{GHz}$ will be the best resource in the near future and high frequency bands above $6 \mathrm{GHz}$ might be introduced in 2020 or after 2020. Spectrum proposed for $5 \mathrm{G}$ in different countries are china (25-30 $\mathrm{GHz}, 40-50 \mathrm{GHz}, 71-76 \mathrm{GHz}, 81-86 \mathrm{GHz})$, Japan $(14,28$, 40, 48, $80 \mathrm{GHz})$, Korea $(66-74 \mathrm{GHz}, 50.4-52.6 \mathrm{GHz}, 37-$ $42.5 \mathrm{GHz})$, UK (10.125-10.2254 GHz, 31.8-33.4 GHz, 40.5-43.5 GHz and 66-71 GHz) and US (27.5-29.5 GHz, 50.4-52.6 GHz and 59.3-71 GHz) $[1,24]$. Some of the new spectrum after WRC-15, above $6 \mathrm{GHz}$ frequency bands tested and conducted by many countries $[25,26]$. Samsung (Korea) tested above $6 \mathrm{GHz}$ frequency band, especially at $13.4-14 \mathrm{GHz}, 18.12-18.6 \mathrm{GHz}, 27.02-29.5$ $\mathrm{GHz}$ and 38.0-39.5 GHz. Samsung achieved $1 \mathrm{~GB} / \mathrm{s}$ rate within 200 meters and BER $0.01 \%$ by employing 64 antennas and adaptive beam forming. The frequency bands which are reframed or below $6 \mathrm{GHz}$, are been included in 5G spectrum [24], but below $6 \mathrm{GHz}$ the bandwidth has got utilized, because of this it is necessary to use above $6 \mathrm{GHz}$ in $5 \mathrm{G}$ technology.

\subsection{Key Technologies in $5 \mathrm{G}$}

The below section will be focused on various features and key technologies, which will play a vital role in the development of the $5 \mathrm{G}$ mobile communication system.

\subsubsection{Massive MIMO}

In the future generation cellular network there is a huge demand for higher data throughput. Because every year, the data traffic is increasing rapidly, one of the main goals of $5 \mathrm{G}$ technology is to achieve 1000 times more than the current data throughput. This can be achieved by placing more number of antenna arrays at the BS with proper separation between the antennas [27,28]. This technology is known as massive MIMO, which is advanced then MIMO. The area throughput model can be expressed as,

Area Throughput $\left(\mathrm{bit} / \mathrm{s} / \mathrm{Km}^{2}\right)=$ Bandwidth $(\mathrm{Hz}) \times$ Cell density $\left(\right.$ cell/ $\left./ \mathrm{Km}^{2}\right)$ x Spectral efficiency (bit/s/cell) 
This formula explains how to increase the area throughput by allocating more bandwidth, more number of cells with separate access point and transmission efficiency. These all are the main factors to achieve the higher area throughput. Massive MIMO is the advanced MIMO technology where a multiple number of antennas at BS and user terminals. Basically two types of massive MIMO proposed by the researchers [28], one is point to point MIMO and another one is multiuser MIMO. In point to point MIMO the structure is like multiple numbers of antennas will be available at both user terminal and BS and in multiuser MIMO only BS contains a more number of antennas irrespective of a user terminal. In future, this multiuser massive MIMO going to play a major role for higher data communication and it is the most scalable technique because the wavelength used for this technology will be 5 to $30 \mathrm{~cm}$ and frequency range will be 1 to $6 \mathrm{GHz}$ [27].

\subsubsection{Millimeter Wave Mobile Communication}

Millimeter wave mobile communication is one of the popular and expected technologies, in the future generation cellular network due to the available ultra broadband spectrum. The demand for higher data rate and high quality communication for smart phones and many smart devices are increasing day by day. In future the capacity of mobile network is going to increase more than a thousand times, as compared with current $4 \mathrm{G}$ technology [30]. A lot of researches and studies are going on millimeter wave communication because of its bandwidth. The frequency ranges for millimeter wave communications are $6 \mathrm{GHz}, 14 \mathrm{GHz}, 28 \mathrm{GHz}, 38 \mathrm{GHz}, 60$ $\mathrm{GHz}, 71-76 \mathrm{GHz}$ and $81-86 \mathrm{GHz}$ [29]. Because of its higher frequency the propagation loss will be more as compared with the lower frequencies, due to this factor the transmission range will be limited, so this millimeter wave communication will be better suited for small cells. To design a channel for millimeter wave bands is complex and challenging. Many organizations have proposed a channel model for this band like, map based channel, Saleh-Valenzuela (S-V) model and Spatial Channel Model (SCM) [29]. In current 3G/4G also based on SCM model so the extension of this model might be the model for $5 \mathrm{G}$ system.

\subsubsection{Non Orthogonal Multiple Access (NOMA)}

By now the users have experienced a tremendous data speed in 4G LTE system, the multiple access technique (OFDMA/SC-FDMA) is the core technique for the current $4 \mathrm{G}$ system [33]. NOMA will be one of the new multiple access technology for next generation cellular network. The higher level target of this technology is to achieve higher energy efficiency, flexible air interface, smart spectrum use, multiple antenna and versatile network solution $[31,32]$. NOMA uses the power level to separate signal from each other. This is totally a new multiple access technology, which is not even used in $2 \mathrm{G} / 3 \mathrm{G} / 4 \mathrm{G}$. NOMA is a non-orthogonal technique which will be introduced either in time, code or frequency.

\subsubsection{Generalized Frequency Division Multiplexing (GFDM)}

GFDM is one of the new multiplexing techniques for future generation mobile communication. GFDM is similar to the OFDM technique, but the carriers are nonorthogonal to each other. The advantage of GFDM will be reduced PAPR and lesser Out of Band emission (OOB) [34]. The other important feature of GFDM, that is signal processing will not be fully complex as compared with OFDM and maintain GFDM signal dense in time. OOB emission is one of the important processes in this technique [34]. To reduce this emission it is required smoother transmission between the GFDM blocks. Many theories for future GFDM have been proposed by the researches. Gabor transforms is one of the popular theory for GFDM, the Balian low theorem is for the modulation and a poission summation algorithm for the reception of each symbol. The channel estimated for GFDM technique is Least Square (LS) and linear MMSE. To achieve the lower PAPR, low OOB emission and higher throughput its necessary to combine MIMO with GFDM technique. MIMO-GFDM transmission and deduction will make the $5 \mathrm{G}$ communication strong [35].

\subsubsection{Beam Division Multiple Access (BDMA)}

A lot of multiple access technologies like Frequency Division Multiple Access (FDMA), Time Division Multiple Access (TDMA), Code Division Multiple Access (CDMA) and OFDM were adopted for 2G/3G/4G. Korean research and development proposed a new multiple access technology for future generation cellular network $(5 \mathrm{G})$, which is known as BDMA. The higher target of this technology is to achieve high quality services and higher system capacity [1, 36]. On BDMA environment, each antenna at $\mathrm{BS}$ is focused on each individual user, the communication between the BS and the MS are in LOS. BS will be monitoring the position of the users, according to the position it will calculate the direction and width of the beam for users [1]. 


\subsubsection{Filter Bank Multicarrier (FBMC)}

FBMC is the one of the multicarrier modulation technique for future generation cellular communication. It is similar to the OFDM technique; where in OFDM CP is used to avoid the Inter Symbol Interference (ISI) but in FBMC, bank of filters will be used instead of CP $[1,3]$. This will proficiently use the bandwidth irrespective of $\mathrm{CP}$ in OFDM. This technique is more advanced than the OFDM because the advantage of FBMC is more as compared with the OFDM. FBMC filters are used to control the adjacent frequency leakage. The delay spread can also be handled properly by this technique [37]. In future, FBMC can be integrated with cognitive radio technology to achieve the better spectrum efficiency and QoS.

\subsubsection{Device to Device Communication (D to D) for $5 G$}

Device to device communication is the communication between two or more user devices without the intervention of a base station. This technology will improve the spectral efficiency and energy efficiency in cellular networks. The proposed routing scheme for $\mathrm{D}$ to D cellular communication [38] is shown in Figure 15.

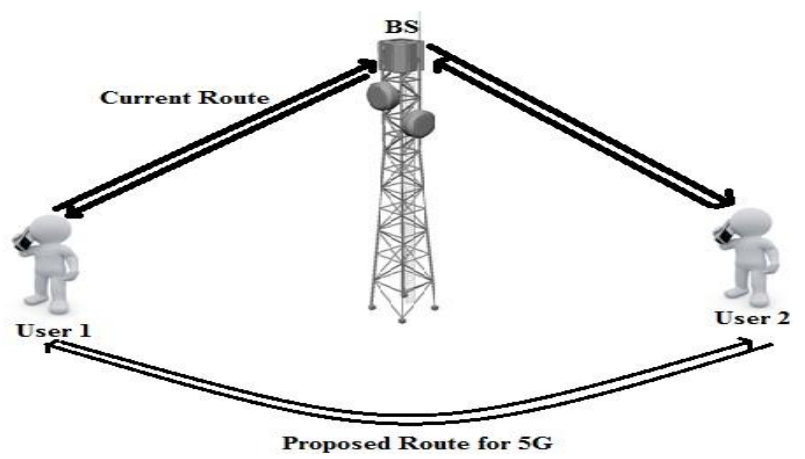

Figure 15. Device to device communication for 5G.

Consider a scenario on efficient data communication between two users attached to the same femto cell, here the cell contains users and BS, the current routing of user1 and user2 is through BS, but the proposed routing shows no involvement of BS, in fact user1 and user2 can communicate directly. This proposed routing scheme will be implemented in next generation cellular communication. This project was proposed by P.Mach, Z.Becvar, T.Vanek (duration: 2017 to 2019), this project is focused on D to D communication [39], combining conventional RF bands and Visible Light Communication (VLC), it is funded by Czech science foundation.

\subsubsection{Cognitive Radio}

Cognitive radio is one of the intelligent technologies for future generation network. In this technology, the transmitter and receiver will function smartly. The main focus of this technology is to use the unused spectrum efficiently, by dynamic spectrum access. The cognitive system will detect the unused spectrum dynamically and allocate that spectrum to the users those who are in need, without any interference with the other users $[1,3]$. The features of cognitive radio are spectrum sensing, spectrum sharing, transceiver geographic location finding, output power adjustments and modulation characteristics. Spectrum sensing and spectrum sharing are the major part of this technology. Spectrum sensing is the sense the free spectrum of the licensed users, and allocates that spectrum to the unlicensed users, without any interference to the licensed users $[3,40]$. In this way, it is possible to utilize the spectrum more proficiently and maintain the communication also in an efficient manner. There are lots of spectrum sensing methods were adopted for the cognitive radio [41] those are, energy detection, cyclostationary and matched filter detection [3, 42], these are all the popular and successful methods adopted for this technology. Implementation of this technology has been already tested in the Femto cell environment. By using cognitive radio technology, Femto cell environment can be able monitor and frequency channel allocation can be possible [43]. The requirements of 5G technology can be fulfill by this technology. The regulatory body like the FCC (USA) and Ofcom (UK) are looking for the emerge of cognitive radio ideas.

\subsubsection{Visible Light Communication (VLC)-5G}

VLC is the optical wireless technology designed for higher data rate communication. From the study, data traffic will be going to increase 24 Exabyte /Month by 2019 [44]. To overcome from this traffic, new technology has to be adopted. Li-Fi is an emerging technology for next generation communication, working on visible light spectrum from 400 to $490 \mathrm{THz}$ frequency range. $\mathrm{Li}-\mathrm{Fi}$ uses hybrid LED's as a source for continuous data transmission at transmitter side and photo detector at the receiver end [45]. More modulation schemes have been proposed for 5G-VLC technology, OFDM is one of the popular modulation techniques to increase the VLC capacity. The target of this technology is to achieve the better QoS even in NLOS communication and higher data rate in indoor communication [1,44]. So we can expect $\mathrm{VLC}$ can be one of the promising technologies for $5 \mathrm{G}$. 


\subsubsection{Femto Cell}

Femto cell is a small base station designed for indoor communication [1]. The main motive of this technology is to provide a better signal coverage for indoor communication. From the study of the cellular environment, more number of voice and data traffic arise from indoor area, but the coverage is less in indoor as compared to an outdoor area, this is one of the major issues in the current cellular environment. To overcome from this problem, the signal from the macro cell can be given to Femto cell BS so that users can experience better coverage with higher data rate. The coverage area of Femto cell is around 10-50 meters. Due to the increased traffic in indoor communication, Femto cell is the most expected technology in $5 \mathrm{G}[1,46]$.

\section{PROJECTS ON 5G}

\subsection{GPPP (5G Infrastructure Public Private Partnership)}

This project started by the EU commission and industry manufactures. The objective is to provide reconfigurable hardware and software, which can support 5G infrastructure. The devices are highly reconfigurable, versatile and flexible for smooth operation on 5G technology [47].

\subsection{G Norma}

This project started by the EU commission and industry manufactures. The main objective of this project is to provide a hilarious architecture for $5 \mathrm{G}$ technology; it includes security, performance and efficient data communication [48].

\subsection{METIS-II (Mobile and Wireless Communication Enables for 2020 Information Society-II)}

This project started by the EU commission and industry manufactures. The main motive of this work is to design a $5 \mathrm{G}$ radio access network and to provide a technical need for an efficient integration for 5G technology. This project focused on networking and security part [49].

\subsection{G X Haul}

The main objective of this project is to dynamically reconfigurable optical- wireless back haul/front haul with the cognitive control plane for small cells and cloud RAN's. This project focused on connecting small cell to core network [50, 51].

\subsection{G Now}

The 5G Non orthogonal waveform for asynchronous signaling (5G Now) is a European project, funded by the EU commission, which is started on Sep 2012. The aim of this project is to increase the performance of single cells by enforcing synchronism and orthogonality [52].

\subsection{CogNet}

Cognitive Network (CogNet) is a 5GPPP project funded by European commission with the cost of 5,972,820€. This project period is from July 2015 to Dec 2017. The CogNet project was designed for making a network as an intelligent for future generation network [53]. The target of this project is to improve the QoS, reduced cost, optimized solution and improved resource utilization [54].

\subsection{KOI}

Koordinierle Indutriekommunikation (KOI) is a European project funded by the Bundesministerium for Bildung und Forschung (BMBF). The duration of this project from Jan 2015 to June 2017. The aim of this project is to utilization of frequency bands, heterogeneous radio access without any interference to the other radio using the same band $[55,56]$

\subsection{MiWEBA (Millimeter Wave Evolution for Backhaul and Access)}

MiWEBA project is funded by the Japan government. The duration of this project from June 2015 to May 2016. The aim of this project is to increase the capacity of the network more than a thousand times from the current capacity, with the nominal cost [57]. The another goal of this project is to use the unused millimeter wave bands. This has been already completed successfully and got an excellent score from MIC and EU [58].

\section{CONCLUSION}

This article is focused on the study of the past, present and future generation mobile communication and it includes the background of the mobile communication system, key technologies and projects. In this work, the detailed study and problem formulation of $3 \mathrm{G}$ and $4 \mathrm{G}$ technology were addressed and it gives a roadmap to the future generation mobile communication which is known as 5G. Spectrum Scarcity is one of the major issues in the current mobile communication scenario, this work suggested a new technology and techniques like Cognitive Radio, FBMC 
modulation, GFDM, Massive MIMO, Femto cell and mmWave communication to solve the problems in current mobile communication. This work also gives a key capability and detailed technical requirements for $5 \mathrm{G}$, this technology will be integrated with the existing technologies like $3 \mathrm{G}$ and $4 \mathrm{G}$. It will bring a new change in the area of mobile communication. In future, $5 \mathrm{G}$ is going to connecting a billion of devices and provide an intelligent service to the mobile world.

\section{REFERENCES}

[1] Kumar. A, Gupta. M, A review on activities of fifth generation mobile communication system, Alexandria Engineering Journal, Elsevier: pp-1-11, Feb 2017, DOI: https://doi.org/10.1016/j.aej.2017.01.043.

[2] Kumar. A, Gupta. M, Design, comparative study and analysis of CDMA for different modulation techniques, Egyptian Informatics Journal, Elsevier: 16(3), pp. 351-365, 2015. DOI: http://dx.doi.org/10.1016/j.eij.2015.07.004.

[3] Pandi. N, Kumar. A, A Review on Cognitive Radio for Next Generation Cellular Network and its Challenges, American Journal of Engineering and Applied Sciences: Vol.10, No.2, pp. 334-347, April 2017. DOI: 10.3844/ajeassp.2017.334.347.

[4] Jiang. D and Liu. G - An overview of 5G requirements- $5 \mathrm{G}$ mobile communications, Spinger: pp. 3-26, 2017. DOI: 10.1007/978-3-319-34208-5_1.

[5] Tinatin. M, Evolution mobile wireless communication and LTE networks, Application of Information and Communication Technologies (AICT), IEEE: pp. 1-7, Dec 2012. DOI: 10.1109/ICAICT.2012.6398495.

[6] Sheikh, Asrar - Wireless communication- Theory and Techniques; Springer US: 2004.DOI: 10.1007/978-1-4419-9152-2.

[7] Proakis. J, Salehi. M- Fundamentals of communication system: Pearson Education. 2008.

[8] Akira. I- Electromagetic wave propagation, Radiation and scattering; second edition; IEEE press wiley, July 2017.

[9] E. A. Alyan, M. S. Anuar, C. B. M. Rashidi, Analysis of theoretical and simulated performance of indoor optical wireless system based on CDMA technology, Electronic Design, IEEE: pp.64-69, Jan 2017. DOI: 10.1109/ICED.2016.7804629.

[10] Olanrewaju B. Wojuola, Stanley H. Mneney, Viranjay M. Srivastava, CDMA in signal encryption and information security, Information Security for South Africa (ISSA), IEEE: pp.56-61, Jan 2017. DOI: 10.1109/ISSA.2016.7802929.

[11] Javier Gozalvez, First Commercial LTE Network, IEEE Vehicular Technology Magazine, IEEE Journals \& Magazines: pp.8-16, 2010. DOI: 10.1109/MVT.2010.936656.

[12] Carlà L, Fantacci R, Gei F, Marabissi D, Micciullo L, LTE enhancements for public safety and security communications to support group multimedia communications, IEEE Network: 30(1), pp.80-85, Feb 2016. DOI: 10.1109/MNET.2016.7389835.

[13] Ghosh A, Ratasuk R, Mondal B, Mangalvedhe N, Thomas M, LTE-advanced: next-generation wireless broadband technology, IEEE Wireless Communications: 17(3), pp.10-22, 2010. DOI: 10.1109/MWC.2010.5490974.

[14] Chih-Cheng Tseng, et al, Fast game-based handoff mechanism with load balancing for LTE/LTE-A heterogeneous networks, Journal of Network and Computer Applications, Elsevier: 85(1), pp-106-115, May 2017.2 DOI: https://doi.org/10.1016/j.jnca.2016.12.002

[15] Syed A hanson-3GPP LTE Radio and cellular Technology-Evolution; Taylor and Francis group; 2016.

[16] Aldmour I, Wireless broadband tools and their evolution towards 5G networks, Wireless Personal Communications, Springer: 95(4), pp.1-26, March 2017. DOI: https://doi.org/10.1007/s11277-0174058-x.

[17] Scholl.H- E-Government information, technology and transformation; AMIS; London; 2010.

[18] Pandi. N, Kumar. A, Analysis of OFDM System with Energy Detection Spectrum Sensing, Indian journal of science and technology: 9(16), pp. 1-6, April 2016. DOI: $10.17485 / \mathrm{ijst} / 2016 / \mathrm{v} 9 \mathrm{i16} / 90230$.

[19] Kumar.A , Gupta. M, A Review on OFDM and PAPR Reduction Techniques, American Journal of Engineering and Applied Sciences: 8(2), pp. 202209, May 2015. DOI: 10.3844/ajeassp.2015.202.209.

[20] Kumar. A , Gupta. M, Design of 4: 8 MIMO OFDM with MSE Equalizer for Different Modulation Techniques, Wireless personal communication: 95(4), pp.4539-4560, August 2017. DOI: DOI: 10.1007/s11277-017-4099-1.

[16] Lukas Wezranowski, Lubomír. Ivanek, Zdenek, Urban, Yahia Zakaria, Optimization of Antenna System for MIMO Technology, Proceedings of the First International Scientific Conference "Intelligent Information Technologies for Industry, Springer: 451, pp.459-469, 2016. DOI: https://doi.org/10.1007/978-3-319-33816-3_45.

[22] Hsuan-Fu Wang, et al, Channel Equalization for MIMO LTE System in Multi-path Fading Channels. Frontier Computing, Springer: 375, pp.697-704, April 2016. DOI: https://doi.org/10.1007/978-981-10-0539-8_68.

[23] Kumar A, Gupta.M, Key Technologies and Problems in Deployment of 5G Mobile Communication System, Communications on Applied Electronics: 1(3), pp.4-7, 2015.

[24] Tan. Wang, Gen. Li,- Spectrum Analysis and Regulations for 5G-5G mobile communications; Spinger: pp. 27-50, 2017. DOI: 10.1007/978-3-31934208-5_2. 
[25] Shafi, Mansoor, et al, 5G: A Tutorial Overview of Standards, Trials, Challenges, Deployment, and Practice, IEEE Journal on Selected Areas in Communications: 35(6), pp.1201-1221, 2017. DOI: 10.1109/JSAC.2017.2692307.

[26] Ancans, Guntis, et al. Spectrum considerations for 5G mobile communication systems, Proceedia Computer Science, Elsevier: 104, pp.509-516, 2017. DOI: https://doi.org/10.1016/j.procs.2017.01.166.

[27] Piyush. V, Gupta. M, Kumar. A, Massive-MIMOPast, Present and Future: A Review, Indian Journal of Science and Technology, 9(48), 2016. DOI: 10.17485/ijst/2016/v9i48/99891.

[28] Trinh Van Chien, Emil Björnson- Massive MIMO Communications-5G mobile communications; Spinger: pp. 77-116, 2017. DOI: 10.1007/978-3319-34208-5_4.

[29] Wang. Y, Shi. Z- Millimeter-Wave Mobile Communications-5G mobile communications; Spinger: pp. 117-133, 2017. DOI: 10.1007/978-3319-34208-5_5.

[30] Bogale, Endeshaw T, Le. L, Massive MIMO and mmWave for $5 \mathrm{G}$ wireless HetNet: Potential benefits and challenges, IEEE Vehicular Technology Magazine: 11(1), pp.64-75, 2016. DOI: 10.1109/MVT.2015.2496240.

[31] Razav. R, et al- Non-Orthogonal Multiple Access (NOMA) for Future Radio Access-5G mobile communications; Spinger: pp. 135-162, 2017. DOI: 10.1007/978-3-319-34208-5_6.

[32] Islam, SM. Riazul, et al, Power-domain nonorthogonal multiple access (NOMA) in 5G systems: potentials and challenges, IEEE Communications Surveys \& Tutorials: 19(2), 2017. DOI: 10.1109/COMST.2016.2621116

[33] P. Wang, J. Xiao, and L. P, Comparison of orthogonal and non-orthogonal approaches to future wireless cellular systems, IEEE Veh. Technol. Mag: 1(3), pp. 4-11, Sep. 2006. DOI: 10.1109/MVT.2006.307294.

[34] Matthe. M, et al,- Generalized Frequency Division Multiplexing: A Flexible Multi-Carrier Waveform for 5G-5G mobile communications; Spinger: pp. 223-257, 2017. DOI: 10.1007/978-3-319-342085_9.

[35] D. Zhang, M. Matthé, L. Mendes, G. Fettweis, A Markov Chain Monte Carlo algorithm for nearoptimum detection of MIMO-GFDM signals, in Proc. IEEE Int. Symp. on Personal, Indoor and Mobile Radio Commun. (PIMRC): pp.281-286, Hong Kong, $2015 . \quad$ DOI: 10.1109/PIMRC.2015.7343310.
[36] Choi, Yong I, et al, On the Performance of Beam Division Nonorthogonal Multiple Access for FDDbased Large-scale Multi-user MIMO Systems, IEEE Transactions on Wireless Communications: 16(8), pp. 5077 - 5089, 2017. DOI: 10.1109/TWC.2017.2705111.

[37] Mattera. D, Tanda. M, Bellanger. M- New Multicarrier Modulations for 5G-5G mobile communications; Spinger: pp. 165-202, 2017. DOI: 10.1007/978-3-319-34208-5_7.

[38] L. Lei, Y. Kuang, X. Shen, C. Lin, Z. Zhong, Resource control in network assisted device todevice communications: solutions and challenges. IEEE Commun. Mag: 52(6), pp.108-117, 2014. DOI: 10.1109/MCOM.2014.6829952.

[39] Saeik Firdose, Challenges on the Validation of D2D Communications: Availability of Open-source Tools, Technical report, DOI: 10.13140/RG.2.2.29942.80967.

[40] Y. Chen, Q. Zhao, A. Swami, Distributed spectrum sensing and access in cognitive radio networks with energy constraint, IEEE Trans. Signal Process: 57(2), pp.783-797, 2009. DOI: 10.1109/TSP.2008.2007928.

[41] Li. G, et al- Spectrum Sharing for $5 \mathrm{G}-5 \mathrm{G}$ mobile communications; Spinger, pp. 51-73, 2017. DOI: 10.1007/978-3-319-34208-5_3.

[42] Pandi N, kumar. A,-Matched Filter detection Spectrum Sensing in Cognitive Radio; Electronics World, Vol.123, No.1972, May 2017.

[43] Xiang, Jie, et al, Downlink spectrum sharing for cognitive radio femtocell networks, IEEE systems journal: 4(4), pp.524-534, 2010. DOI: 10.1109/JSYST.2010.2083230.

[44] Zvanovec. S, et al, Visible light communication towards 5G, Radio engineering: 24(1), pp.1-9, 2015. DOI: 10.13164/re.2015.0001.

[45] Dinesh. K, Kumar. N, Incredible innovation in visible light communication- light fidelity (li-fi), International journal of engineering sciences \& research technology: 4(8), 2015.

[46] Mavromoustakis, Constandinos, George. Mastorakis, and Jordi Mongay Batalla-Internet of Things (IoT) in 5G mobile technologies;Springer: 8 . 2016.

[47] 5G infrastructure public private partnershiphttps://5g-ppp.eu/.

[48] 5G Norma- Novel Radio Multiservice adaptive network architecture-https://5gnorma.5g-ppp.eu/.

[49] Elayoubi, Salah Eddine, et al, 5G service requirements and operational use cases: Analysis and metis ii vision, Networks and Communications 
(EuCNC), 2016 European Conference on. IEEE: 2016.

[50] Arnold, Paul, et al, 5G radio access network architecture based on flexible functional control/user plane splits, Networks and Communications (EuCNC), 2017 European Conference on. IEEE: 2017.

[51] 5G XHaul-Dynamically Reconfigurable OpticalWireless Backhaul/Fronthaul with Cognitive Control Plane for Small Cells and Cloud-RANshttp://www.5g-xhaul-project.eu/.

[52] 5G Now- Non-Orthogonal Wavform for asynchronous signalling-http://5gnow.eu/.

[53] Xu, Lei, et al, CogNet: A network management architecture featuring cognitive capabilities, Networks and Communications (EuCNC), 2016 European Conference on. IEEE: 2016.

[54] CogNet- Building an Intelligent System of Insight and Action for 5G Network Managementhttp://www.cognet.5g-ppp.eu/.

[55] Holfeld, Bernd, et al, Wireless communication for factory automation: An opportunity for LTE and 5G systems, IEEE Communications Magazine: 54(6), pp.36-43, 2016.

[56] KOI- Koordinierte Industriekommunikation; Fraunhofer Institute for Telecommunications, Heinrich Hertz Institute, HHIhttps://www.hhi.fraunhofer.de/en/ departments/wn/ projects/koi.html.

[57] Weiler, Richard J, et al, Quasi-deterministic millimeter-wave channel models in MiWEBA, EURASIP Journal on Wireless Communications and Networking: 2016.

[58] MiWEBA- Millimeter Wave Evolution for Backhaul and Access- https://www.miweba.eu/\#Start. 